OPEN ACCESS

Edited by: Stephan Pauleit, Technical University of

Munich, Germany

Reviewed by:

Simon Bell,

University of Edinburgh,

United Kingdom

Ann Van Herzele,

Radboud Universiteit, Netherlands

${ }^{*}$ Correspondence:

Lorien Nesbitt

lorien.nesbitt@ubc.ca

tThese authors have contributed equally to this work and share first authorship

Specialty section:

This article was submitted to Urban Greening,

a section of the journal

Frontiers in Sustainable Cities

Received: 14 June 2020 Accepted: 29 September 2020 Published: 02 November 2020

Citation:

Sax D, Manson C and Nesbitt $L$ (2020) Governing for Diversity: An Exploration of Practitioners' Urban Forest Preferences and Implications

for Equitable Governance.

Front. Sustain. Cities 2:572572 doi: 10.3389/frsc.2020.572572

\section{Governing for Diversity: An Exploration of Practitioners' Urban Forest Preferences and Implications for Equitable Governance}

\author{
Daniel Sax ${ }^{\dagger}$, Corbin Manson ${ }^{\dagger}$ and Lorien Nesbitt* \\ Department of Forest Resources Management, Faculty of Forestry, University of British Columbia, Vancouver, BC, Canada
}

Urban forests are increasingly acknowledged as sources of multiple benefits and central to climate resilience and human well-being. Given these diverse and significant benefits, it is important to govern urban forests so as to ensure that all residents have equitable access and enjoyment. Understanding urban forest preferences, and including them in planning and management, is a key aspect of informed and contextually relevant urban forest governance. Although many studies have examined public urban forest preferences, we lack an understanding of the preferences of a key stakeholder: urban foresters. This study presents the results of semi-structured interviews with 22 urban forestry and allied green practitioners focused on preferred and least-preferred aspects of the urban forest. Participants expressed their preferred urban forest characteristics according to four themes: administration, spatial attributes, naturalness, and social benefits. Least-preferred characteristics were expressed under the themes of administration and degradation. Results suggest that practitioners employ a systems-level lens when discussing urban forest preferences. However, they also draw on personal experience when constructing their preferences, particularly in relation to naturalness and spatial diversity. These results provide insight into the urban forest preferences of practitioners and highlight the importance of innovative approaches, such as mosaic governance in urban forestry, to facilitate a just integration of the diverse preferences of urban forest stakeholders.

Keywords: urban forest governance, urban green equity, urban forest preference, mosaic governance, recognitional justice

\section{INTRODUCTION}

\section{Urban Forestry}

The influence of urban areas extends beyond their formal geographical boundaries to impact nearly every part of the planet (Brenner and Schmid, 2017). In addition to their global reach, cities are home to ever-increasing human populations, with $55 \%$ of all humans currently living within urban areas (United Nations, 2018). Solving the novel challenges related to urban environments is important to human and environmental health, and the need to find solutions is growing more urgent (Dodman, 2017). Urban forests, also sometimes referred to as "green infrastructure" and "green space," are defined as the trees and associated vegetation in both public and private urban areas, and include multiple "green" elements of urban socio-ecological systems, such as street trees, 
parks, backyard trees and gardens, and remnant woodlands (Konijnendijk et al., 2006). These urban forest systems may hold a solution to the challenges experienced in urban environments. Current research suggests that the ecosystem services offered by urban forests can improve the mental and physical health of urban dwellers, mitigate the impacts of climate change, and offset the environmental impacts of growing carbon footprints (Elmqvist et al., 2015).

Urban forests and associated green spaces offer myriad ecological, economic, and social benefits (Nowak and Crane, 2002; Escobedo and Nowak, 2009; Wolf et al., 2015; Nesbitt et al., 2017) beyond those of traditional gray infrastructure-e.g., concrete pipes and wastewater treatment plants (Voskamp and van de Ven, 2015). Urban forests can help mitigate air, water, and noise pollution while also providing flood mitigation and water retention (McPhearson et al., 2016). Cultural ecosystem services, such as the provision of recreational spaces, aesthetic pleasure, or spiritual experiences, distinguish the urban forest as an essential facet of urban livability (Riechers et al., 2016). The social benefits offered to residents by urban forests are complemented by public health improvements that can increase well-being (Elmqvist et al., 2015). People who frequent urban parks have lower overall mortality rates and better mental health outcomes compared to individuals who do not (Shanahan et al., 2015). Urban residents also seek relief from excessive heat in green areas. This is especially important for the elderly seeking to reduce their risk for heat-related illness or death (Arnberger et al., 2017). In terms of social outcomes, high quality, accessible green spaces can also lead to the formation of stronger bonds within urban communities (Arnberger and Eder, 2012).

\section{Urban Green Equity}

The diverse benefits of urban forests suggest that they can contribute positively to the environmental and social quality of urban areas. Research in the field of urban green equity, however, has revealed that not all urban residents enjoy equitable access to urban forests or their benefits (Heynen et al., 2006; Nesbitt et al., 2018, 2019). In the United States, for example, researchers have uncovered a correlation between average neighborhood income and tree canopy cover (Landry and Chakraborty, 2009; Schwarz et al., 2015). Moreover, it has been shown that vegetation of any sort is more prevalent in areas with higher socioeconomic status and that historically marginalized residents and residents with lower incomes and education often have less access to urban vegetation (Nesbitt et al., 2019). Paradoxically, even in areas where historically marginalized residents have equal or better spatial access to green spaces, many parks are unsafe or poorly maintained, which may discourage use and prevent residents from realizing the available benefits of green infrastructure (Smiley et al., 2016). Thus, it isn't enough to consider spatial accessibility alone. Social accessibility - a function of how an urban forest aligns with the needs and wants of stakeholders (Weiss et al., 2011)-must also be taken into account when discussing equitable access to urban forest benefits (Weiss et al., 2011; Smiley et al., 2016). It is essential, then, that preferences for urban forest attributes be featured prominently in the design, implementation, and management of urban forests.

\section{Urban Forest Preferences}

A robust understanding of urban forest preferences is a first step toward more informed and contextually relevant urban forest governance (Rishbeth, 2004; Lindemann, 2019); however, ascertaining urban forest user preference can prove challenging. Research has revealed that people's preferences vary according to a range of sociocultural and geographic influences (Fraser and Kenney, 2000; Koo et al., 2013; Peckham et al., 2013; Nesbitt et al., 2018). What's more, preferences are often heterogeneous, even within a single geographic region (Alvarez et al., 2018; Asah and Blahna, 2020). Furthering these complications, there are a range of urban forest stakeholders, beyond urban forest users, to consider when gauging local preference. Prominent amongst these stakeholders are urban forest professionalsplanners, managers, and practitioners directly involved in the design, implementation, and upkeep of urban forests (Asah and Blahna, 2020). Urban forest professionals are those most closely engaged in planning and managing urban forests, and thus play a key role in urban forest governance and represent important perspectives on urban forest preferences (Young, 2010; Conway and Vander Vecht, 2015; Fontaine and Larson, 2016). While many researchers have investigated public preference for urban green spaces and urban forests in terms of local resident experience, few have extended their exploration to urban forest professionals. This is a substantial gap in urban forest preference literature: urban forest professionals possess expertise essential for the implementation and management of urban forestsand play a decision-making role in ongoing planning and management efforts related to urban forests and green spacesyet the preferences of urban forest professionals remain unclear. To build a more equitable and inclusive urban forest, it is essential that we understand the preferences of urban forest professionals and posit governance strategies that integrate their knowledge and perspectives with the contextual understandings of local residents.

\section{Objectives}

This research explores the preferences of urban forest professionals and questions how an understanding of these preferences can inform equitable governance strategies, such as mosaic and distributed governance models. It is our hope that this research can also help urban forest professionals engage in a more reflexive urban forest practice. To achieve these aims, we: (1) explore trends in how urban forest professionals express their preference (or lack of preference) for urban forests in two case study cities; and (2) discuss strategies for urban forest governance that integrate these preferences with contextually relevant understandings of urban forest preferences among the general public. This analysis lends insight into ways in which urban forests can be designed and managed with equity in mind, and helps inform future efforts toward equitable urban forest governance.

\section{MATERIALS AND METHODS}

To explore the preferences of urban forest practitioners, we conducted semi-structured interviews (Schensul et al., 1999; 
Creswell, 2018) with urban forestry professionals in two cities in the United States (U.S.): New York City, New York (New York), and Phoenix, Arizona. Respondents were asked a series of questions intended to ascertain the qualities of areas of the urban forest that they most and least preferred, and were given maps to help guide their answers. Interviews were audio recorded and transcribed verbatim prior to coding in NVivo 12 . We relied on a system of thematic classification (Braun and Clarke, 2006) to code and analyze our data. Following a line-by-line coding process (Creswell, 2018), we sorted respondents' stated preferences for urban forests into themes (Braun and Clarke, 2006). These characterizations serve as the basis for our results and discussion.

\section{Conceptual Framework}

Drawing inspiration from constructivist thought, our approach attends to the context-specific nature of respondent experience and preference (Maxwell, 2013; Creswell, 2018). We strove for flexibility (Fontana and Frey, 2005; Greenspan and Bolkosky, 2006; Vaivio, 2012) within our semi-structured interview schedule in order to remain close to the particularities of respondent reality (Creswell, 2018). The mapping tool provided space for respondents to translate preferences into tangible urban forest elements and relate their abstract considerations for urban forest qualities to areas with which they are familiar. Central to our methodology was a practice of reflexivity among members of the research team. Although qualitative research methods provided us with the capacity to engage with respondent perspectives, it was essential that we recognize the myriad power dynamics at play and the potential for researcher bias within both the interview and analysis process (Wolf, 1996; Sultana, 2007). To grapple with these questions of bias and representation we invited flexibility during the interview process to ensure that respondent perspective and experience would remain the central focus of our data (Fontana and Frey, 2005; Greenspan and Bolkosky, 2006; Vaivio, 2012). In addition, we grounded our analysis in a practice of thematic classification that encouraged us to remain close to respondent mode of expression and to consider the totality of interviews before moving toward interpretation (Braun and Clarke, 2006; Creswell, 2018).

\section{Site Selection}

New York and Phoenix have active urban forestry programs operating at both the municipal and community level and are diverse in terms of climate and demographics. These elements make New York and Phoenix ideal sites for a study of urban forest preferences. There were ample urban forest professionals for us to interview and we were able to capture responses from a diverse range of practitioners across a variety of urban contexts. In doing so, we elicited a broad understanding of preferences and gained insight into a collection of emergent trends both within and across our study sites.

\section{Phoenix}

Phoenix is a low-density urban center (Table 1) located in the southwestern United States (Figure 1). It is majority white with a significant Latinx population (Table 2). The municipal division that manages urban forests is the City of Phoenix Parks and Recreation department, with support from both the Urban Forest Infrastructure Team and the Tree and Shade Task Force (City of Phoenix, 2010). The Parks and Recreation department partners with the Arizona state government as well as other organizations such as Trees Matter, Arizona State University, and the Arizona Community Tree Council to deliver urban forest programming and management services. The city's Tree and Shade Master Plan, published in 2010, outlines the role of urban forests in realizing important developmental goals (City of Phoenix, 2010).

Phoenix's urban forest exists in a desert environment (Table 1). The urban forest canopy covers $\sim 12.4$ percent of the urban area, and the City has established a canopy cover goal of 25 percent by 2030 (City of Phoenix, 2010). Phoenix's urban forest is dominated by Mesquite (Prosopis velutina) at 8.8 percent, followed by Blue Palo Verde (Parkinsonia florida) at 6.8 percent, and Aleppo Pine (Pinus halepensis) at 5.8 percent. The California Fan Palm (Washingtonia filifera) and the Mexican Fan Palm (Washingtonia robust) are also culturally important parts of the urban forest. Although they only comprise 3.8 percent and 3.1 percent of the urban forest canopy, respectively, they are an historically important part of Phoenix's urban forest (City of Phoenix, 2020).

\section{New York City}

New York is a densely populated (Table 1) and diverse (Table 2) metropolis that serves as an economic and cultural hub on the east coast of the United States (Figure 1). With regard to urban forestry, New York City Parks and Recreation is the municipal agency in charge of parks and street trees (New York City Parks Recreation, 2019a). In addition to this work, they also partner with a number of non-profit and community groups such as the New York Restoration Project, Audubon New York, Natural Areas Conservancy, and Trees New York to plan and manage New York's urban forest and offer stewardship programming (New York City Parks Recreation, 2019b). These partnerships have led to a number of successful urban forestry projects throughout the city-e.g., the 2007 MillionTreesNYC Initiative launched with the goal of planting and maintaining 1,000,000 trees within the city by 2017 (McPhearson et al., 2016). Beyond a proven commitment to invest in the urban forest, New York also has programs in place to inventory parks, monitor park use, and document user attitudes and activities (New York City Parks Recreation, 2014).

New York's urban forest exists in a humid subtropical environment (Table 1). The urban forest canopy covers $\sim 21$ percent of the city, augmented by the recent MillionTreesNYC planting initiative (Nowak et al., 2018). New York's urban forest is dominated by Norway Maple (Acer platanoides) at 6.1 percent, Northern White-cedar (Thuja occidentalis) at 5.7 percent, Tree-of-heaven (Alianthus altissima) at 5.5 percent, Sassafras (Sassafras albidum) at 4.7 percent, and White Oak (Quercus alba) at 4.3 percent.

\section{Data Collection}

This study was approved by the Behavioral Research Ethics Board of the University of British Columbia (Approval Certificate 
TABLE 1 | Population and climatic characteristics of Phoenix, AZ and New York City, NY.

\begin{tabular}{|c|c|c|c|c|}
\hline & Population & Population density (residents $/ \mathbf{k m}^{2}$ ) & Mean annual rainfall $(\mathrm{mm})$ & Mean annual temperature $\left({ }^{\circ} \mathrm{C}\right)$ \\
\hline Phoenix, AZ & $1,626,728^{a}$ & $1,029.9^{a}$ & $167^{b}$ & $24.4^{b}$ \\
\hline New York City, NY & $8,622,698^{a}$ & $9,943.3^{a}$ & $1304^{c}$ & $13.1^{\mathrm{c}}$ \\
\hline
\end{tabular}

a United States Census Bureau (2017), b National Oceanic Atmospheric Administration (2019b), c National Oceanic Atmospheric Administration (2019a).

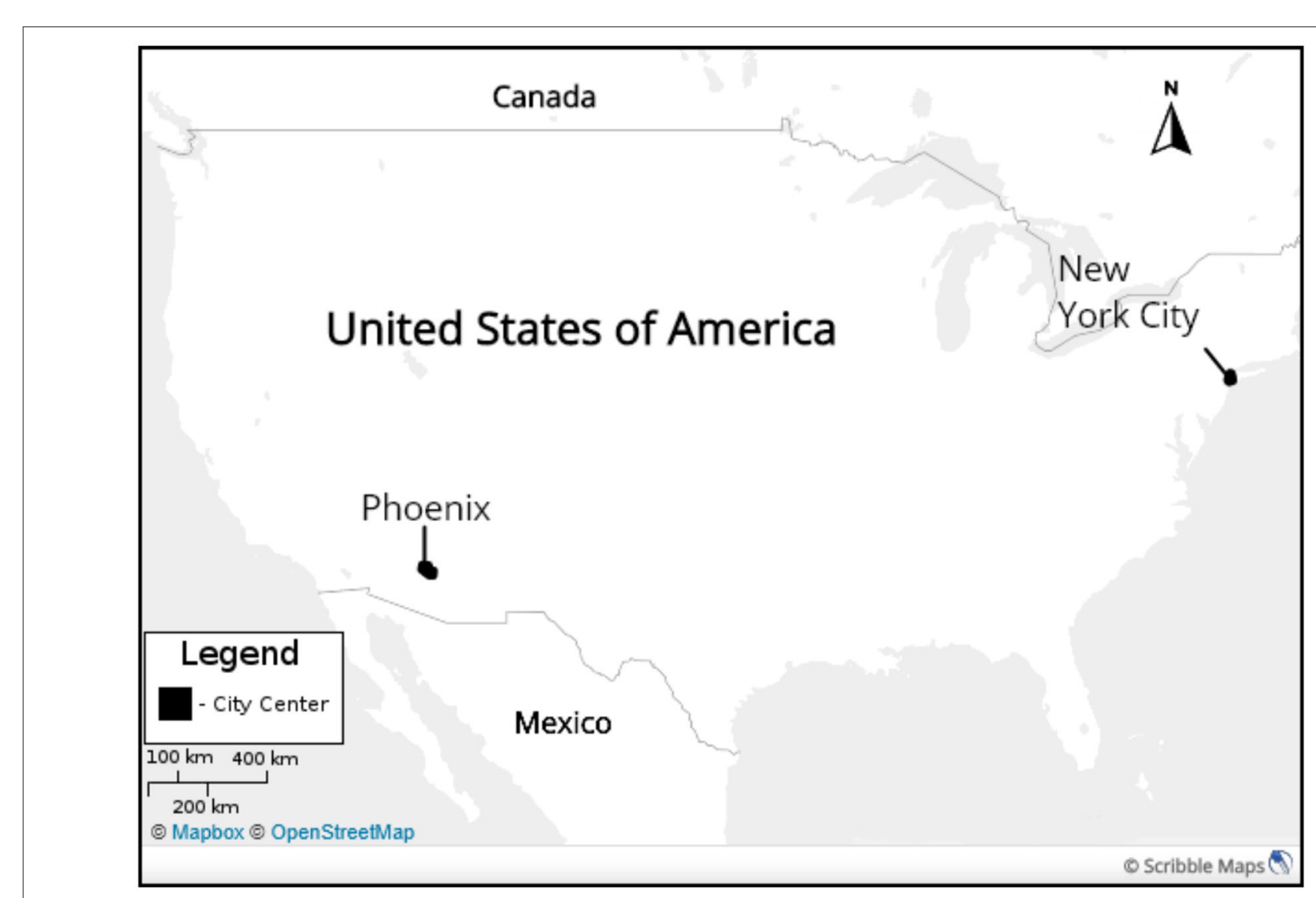

FIGURE 1 | The location of the study sites within North America. Map created using Open Street Maps and Scribble Maps: http://openstreetmaps.org/; https://www. scribblemaps.com/.

Number H16-02583-A002). Our data were collected as part of a larger research project investigating urban green equity in U.S. cities. The interviews lasted between 50 and $100 \mathrm{~min}$, during which participants responded to a series of questions designed to investigate patterns in urban forest decision making and practitioner perspectives on the nature of urban green equity and its role in governance. The interview instrument (Appendix A) was developed collaboratively with the research team following a review of relevant literature. Once completed, it was reviewed by experts in semi-structured interviews and piloted with an expert in urban forest governance. The exact content of each interview differed according to the answers of participants and the discretion of the interviewer (Fontana and Frey, 2005; Greenspan and Bolkosky, 2006; Vaivio, 2012). The final suite of questions sought to explore the elements of urban forests that urban forest practitioners most and least preferred-these questions informed the analysis reported in this study:
- Think about your favorite part of the urban forest (e.g., a certain tree, park, garden). What do you like best about it? Please mark it on the map.

- Think about your least favorite part of the urban forest (e.g., a certain tree, park, garden). What do you dislike most about it? Please mark it on the map.

\section{Preference Mapping}

In addition to verbal responses to interview questions, respondents were asked to discuss their preferred and leastpreferred urban forest attributes in terms of local urban forests. Maps displaying roads, municipal boundaries, and detailed estimates of vegetation cover in respondents' respective cities were presented. As the interview progressed, respondents were periodically asked to circle areas that matched their preferred or least-preferred criteria and provide an explanation. The purpose of the mapping exercise was to help participants 
TABLE 2 | Demographics of Phoenix, AZ and New York City, NY.

\begin{tabular}{|c|c|c|c|c|c|c|}
\hline & White (\%) & African American (\%) & Asian (\%) & American Indian (\%) & Mixed-Race (\%) & Latin $^{a}(\%)$ \\
\hline Phoenix, AZ & 72 & 7 & 4 & 2 & 4 & 43 \\
\hline New York City, NY & 43 & 24 & 14 & 0.4 & 3 & 29 \\
\hline
\end{tabular}

Native Hawaiian/Pacific Islander was omitted as both cities contain less than one percent people in this category.

United States Census Bureau (2017).

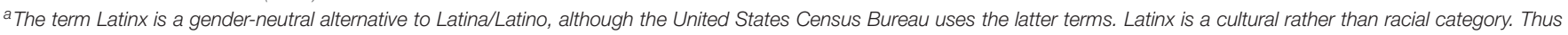
this number represents people of any race who identify as Latinx.

ground their discussions of urban forest preferences and provide detailed responses.

\section{Participant Selection}

In 2016, we contacted municipal and state governments as well as private businesses, NGOs, community organizations, and academic institutions to identify participants. In total, 22 respondents were interviewed for this project: 11 from New York and 11 from Phoenix. Participant characteristics are outlined in Table 3.

We required that respondents be either urban forestry/urban green professionals or volunteers with at least 6 months of experience. Our initial point of contact in each city was the municipal employee in charge of research and partnerships. We followed a process of snowball sampling (Palinkas et al., 2015) to identify subsequent respondents. Our focus was on finding individuals that represented a variety of organizations and sectors involved with management and governance of the urban forest (Table 3). Each respondent was assigned an identifying number to maintain their anonymity.

\section{Thematic Analysis}

We performed verbatim transcription on all audio recorded interviews (Du Bois et al., 1993). We then performed our thematic analysis following the six-step protocol described by Braun and Clarke (2006) using an inductive realist approach. We used NVivo 12 Pro (QSR International Pty Ltd. ${ }^{\left({ }^{2}\right.}$ 2018) for coding the interview data. We also employed credibility checks to ensure coded data were relevant to their codes, and that the coding scheme summarized the entire data set.

\section{RESULTS}

Our analysis identified six primary themes represented within responses. Respondents discussed preferred urban forest elements in terms of administration, naturalness, spatial attributes, and social benefits. There was some overlap in how respondents expressed their least-preferred urban forest elements, grounding their discussion in challenges related to administration, and degradation.

\section{Preferred Urban Forest Traits}

Responses pertaining to preferred areas were grouped into 4 themes-administration, spatial attributes, naturalness, and social benefits.

\section{Administration}

Responses connecting administrative elements to urban forest preference emerged in fifteen of our interviews, particularly related to accessibility and management. A common talking point was urban forest accessibility. Most respondents considered access in terms of an urban forest's nearness to residents-e.g., proximity to the home or to public transit. The importance of this form of accessibility was highlighted by a New York respondent who discussed their experience as a parent.

Yeah, so it's easy, and I don't have a car and I do have a son. So, the accessibility by mass transit, public transportation is important to me. And then also thinking about where I have friends [... if I can combine my trips to a green space with seeing friends who live in these neighborhoods then that's even better [...] I really think of these places as convening spots [...] (NYC-11).

Some respondents, however, incorporated an equity lens into their notion of accessibility, considering the capacity of an urban park to serve its local population. The following excerpt exhibits an alternate conception of accessibility discussed in terms of barriers to access faced by residents.

Big trees, grassy parks, and it's surrounded by a population that's not extremely wealthy. So they have access to the central core, which has this traditional neighborhood, urban feel to it, with the combination of commerce and open space, which is great (PHX-9).

For this respondent, accessibility is a question of who has access to the urban forest as opposed to solely considering what is accessible. Another urban forester in Phoenix thought about accessibility in different terms still, preferring an urban park because of the amenities surrounding it.

I really like the area that we're in right now 'cause you can walk to your restaurant, and right down here, if you go to the post office, right down the way is Civic Space Park [...] (PHX-1).

Respondents also identified management as an important administrative element when selecting preferred urban forest areas. Effective management was described as regular maintenance and improvements to the urban forest, sometimes including stewardship from local communities.

in these more affluent areas where you've had trees growing for a good 30-40 years, and they're full and mature and lush 
TABLE 3 | Breakdown of participant characteristics by (a) sector ${ }^{\star}$ and (b) highest level of education attained.

\begin{tabular}{|c|c|c|c|c|c|c|}
\hline & Municipal government & Regional/state government & NGO & Community Member & Academia & Private business \\
\hline Phoenix, AZ & 9 & 0 & 4 & 1 & 1 & 0 \\
\hline New York City, NY & 6 & 1 & 1 & 1 & 1 & 2 \\
\hline
\end{tabular}

\section{(b)}

\begin{tabular}{|c|c|c|c|}
\hline & Bachelor's degree & Master's degree & $\mathrm{PhD} / J D$ \\
\hline Phoenix, AZ & 4 & 5 & 2 \\
\hline New York City, NY & 4 & 6 & 1 \\
\hline
\end{tabular}

*Some respondents belonged to more than one sector.

[...] You can tell that the trees are maintained. You often have neighborhood organizations that do community tree trimmings or prunings or tree plantings separate of what the city does, and you can see it when you're in these areas (PHX-10).

In Phoenix, flood irrigation was a frequently cited example of effective management.

And then the other area that I would say [...] It's north, it's like where this dark green stuff is. Because they have big giant trees. And they have big giant trees because they're on flood irrigation, and there is ample water to accommodate those big giant trees (PHX-2).

Another Phoenix respondent expressed strong preference for greening initiatives taking place in the downtown area.

I like what Downtown Phoenix Inc is doing in downtown Phoenix. And they luckily have an organization that's dedicated to planting trees in the right-of-way. I think, as in terms of a historic area that's really cool (PHX-6).

Both of these excerpts show strong ties between respondent preference and effective organization and management on the part of municipal actors and property managers. Some respondents preferred areas that had legislative protections in place-namely nature preserves with limited public access-or those that had been managed with wildlife in mind.

And then I really like what Scottsdale has done with the McDowell Preserve. They basically put it off-limits and then turned it into this giant regional park and left it natural vegetation (PHX-6).

One of the reasons why I also love Astoria Park is because it's on the East River, and the East River is one of the national migratory bird routes. And so, if you have a lot of good green space along this river, you'll attract a lot of really amazing birds [... ] (NYC-2).

\section{Naturalness}

Perception of naturalness was a common thread throughout our interviews-nineteen of our respondents drew some connection between naturalness and their preference for urban forest areas.
More than half of all respondents expressed preference for urban forests because of the presence of large or mature trees. Among respondents, there was substantial overlap between discussion of mature trees and other preference elements including abundance and diversity of vegetation and immersion in the urban forest.

And there are just amazing mature trees of every shape and size and species in that park [...] as someone who looks at trees for a living every day, it's hard to just appreciate them for all their beauty and diversity sometimes [...] and that's one of the places where I feel like I can really do that (NYC-10).

I mean you have any area along Prospect Park when we work there but we don't work there that often because it's mostly mature trees, but it's beautiful. And then just south of the park [...] like toward Cortelyou there's all these really large trees. It's like suburban Brooklyn. There's all these beautiful Victorian homes (NYC-7).

The latter excerpt also illuminates a tendency among respondents to draw connections between social and demographic trends and the presence of preferred naturalness elements. In Phoenix, this narrative was common-respondents often associated a mature tree canopy and plant diversity with flood irrigation systems and other indicators of wealth.

When you look at trees and vegetation, it's the stately large vegetated areas, large trees, large palms, whatever you're talking about, large. Very diverse mixture of vegetation, different species. People with a lot of money able to spend. I just love driving through the neighborhoods just looking at the plants. Like this neighborhood, 'cause this is much more homogenous [...] (PHX-4).

The Bridle Path is beautiful [...] There's huge trees there that you don't see in the valley typically, 'cause there's so much flood irrigation so it's like... And people spend a lot of money to live there $[\ldots](\mathrm{PHX}-1)$.

\section{Spatial Attributes}

Nine respondents mentioned spatial attributes when discussing their preferred urban forests. Two points of discussion were 
foundational to respondent discussion of aesthetic attributes: size, and spatial diversity.

Respondents preferred parts of the urban forest that covered relatively large areas; however, size was not discussed as an isolated element. Instead, it was often associated with related impacts such as low-noise levels, peacefulness, and openness. The following two responses illuminate this trend:

It's genuinely quiet. It is expansive for New York City. It's not Yellowstone, but it's expansive. It's representative of our past. The trees are large and gorgeous, and it's peaceful (NYC-1).

[... I I like all this, because it's such a variety of open space areas. So, here we talked about large lots, golf courses, open space. A lot of public or private, common open space areas (PHX-7).

It is not solely the size of the described urban forests that distinguishes them for these respondents, but the effect of the space. What's more, for the latter respondent, there is a uniqueness to each form or urban forest mentioned whether in terms of use or ownership. Many respondents across both study sites echoed this perspective, looking beyond the scale of single urban forest areas to highlight the diversity of landscape features and urban forest areas available to residents.

I think my favorite thing is being able to a degree to discover something new and the fact that there is such a diversity in the landscape in New York City, and being able to share that with people (NYC-8).

It's, yeah, one of my favorite urban forestry experiences. Because you're in a cemetery, and it's this peaceful place, and the use and the experience you have in the place is so different than from a park (NYC-10).

\section{Social Benefits}

Nineteen respondents cited social attributes, including opportunities for recreation, place attachment, and community as influencing their urban forest preferences. It was common for respondents to express preference for urban forest areas in which they had lived or worked. While this result is not in itself surprising, it was illuminating to note the ways in which familiarity with urban forest areas related to other categories of preference. Intimate knowledge of an urban forest area was rarely the sole criterion for preference, rather familiarity led to a deeper understanding of and appreciation for other urban forest attributes. In the following excerpt, a respondent describes a long history with Forest Park in New York.

Forest Park is really cool because I worked there for so long and it was something that was so different and new for me, and being able to be happy or be annoyed and just go for a walk in the park, and also running and going through trails [... ] and being able to just have access to that right outside my office door (NYC-8).

Although there are clear ties between this respondent's history working in the park and their preference for the space, it is not solely a familiarity with Forest Park but the accessibility of trails for walking and running that defined her preference. This trend emerged again during a later interview:

Well, I have to say my own neighborhood, [... I'm on Eastern Parkway, where they just put a bike lane, and planted a bunch of trees, and everything like that (NYC-9).

Familiarity with the Eastern Parkway has a clear influence over the choice to highlight it; however, it is the variety of amenities offered that justify this respondent's expression of preference. As an interesting point of contrast to this concept of familiarity, a number of respondents expressed preference for urban forest areas that offered an escape from the experience of the city. Respondents preferred urban forests that masked the urban environment around them and made them feel elsewhere.

Alley Pond Park is also incredible because you can be there and have no clue that you're in New York City. [...] It is so forested and so out of the way. It's really pretty incredible (NYC-2).

For the above respondent, it is the denseness of the urban forest that provides an escape. A respondent from Phoenix considered escape from a different angle, highlighting the ways in which urban forests allow visitors to experience a new form of city, separated from its urban components.

You're in a city, you're driving in and then you just go a little bit like this and you're in this park and mountain [...] And you're in this environment that's totally not like downtown, which I love. 'Cause you can escape from the urban but you're still in the city (PHX-8).

Citing a subtler instance of escape, another Phoenix urban forester noted the impact of non-native vegetation on visitorand personal-perception of an urban forest area:

I like the Bridle Path [...] probably why it's so neat for people is it's just totally not any vegetation that's natural to here, and so it reminds me of somewhere else (PHX-6).

Whether it is the explicit components of the urban forest or its plant composition, these passages suggest a link between respondent preference and the capacity of an urban forest to cultivate place attachment-a feeling of pride and connection imbued within an contextually important space (Brown et al., 2003). Some respondents gave particular attention to this quality when expressing their preference.

And the thing I like best about it is it has these old trees and there's a closed canopy. And the reason that I like that is because people come to the park specifically for the trees [...] And really comment about how it feels like you're in a forest, or it's really calming, or on a hot day, it's like an oasis. And so it creates such a specific place (NYC-10).

Beyond elaborating on the particular elements of the urban forest that facilitate place attachment, this passage provides insight into how these qualities combine to elicit a unique 
atmosphere. Adjacent to discussion of place attachment, a number of respondents expressed preference for urban forests that foster community. One urban forester from New York called our attention to an urban park that runs along the Hudson River waterfront.

And there's no question about who it is that lives in the adjacent neighborhoods, and you see how people use the park so differently [...] [further South] It's sort of like European park land, open space, flowering plants, benches. You get up more to Harlem and you see there's more ball courts. There's more open space. There's people barbecuing (NYC-4).

This particular urban forest is preferred because it accommodates a range of uses and brings residents' variable interests into a single, communal space. Community was also discussed in terms of an urban forest's capacity to evoke history. In Pheonix, respondents often expressed preference for urban forests that featured reference to local and regional histories.

Encanto Park is one of those parks that floats to the top [...] It's historic, so there's historic aspects to it, which is kind of a nice thing, if you get tied into historic aspects of your community (PHX-2).

In New York, one respondent associated her preference for Central Park its legacy as the first urban park:

I go to Prospect Park a lot, for me Central Park is this special place, not just because I work here but knowing that it was the first urban park, and it literally set off a movement in America and elsewhere for green space in urban environments [...] (NYC-11).

Finally, some urban foresters considered community as a metric of equity-who constituted the community was an essential determinant of their preference.

It's [Indian Bend Wash] a corridor that runs all the way north and south through Scottsdale. Great recreational amenity, connects a variety of classes and wealths and demographics from an age perspective [...] (PHX-9).

[...] there are a lot of homeless people that enjoy [the park] and they're not pushed out or anything, which is good (PHX-1).

\section{Least-Preferred Urban Forest Traits}

Responses pertaining to least-preferred areas were grouped into two themes-administration and degradation.

\section{Administration}

Thirteen respondents mentioned administrative elements as having influence over their determination of least-preferred areas. One common point of discussion was poor managementrespondents regularly identified areas where neglect or mismanagement had resulted in urban forests falling short of their intended use.

It's super frustrating for me to see that all of these trees that absolutely do not belong planted there, are planted there. It is totally the case study of what not to plant in sandy exposed conditions (NYC-4).

Urban forest areas where management plans overlooked site conditions were common sources of frustration. Respondents often expressed dismay at the amount of attention they were asked to give urban forests that they perceived as not worth the time or resources.

the trees that grow there are really crappy, usually invasive trees that are not long-lived. And yet, we're still trying to manage those as forests. And it's so hard because it just feels like we can't. Because there's no native seed bank, or no history of an upland forest habitat, we have to start from scratch and try to create something that really shouldn't be there [...] (NYC-5).

In contrast, a number of respondents identified sites in which they saw unrealized potential. They highlighted areas that they considered ideal candidates for increased urban forest amenities, but they felt were, instead, falling by the wayside. Lamenting a lack of imagination concerning a waterfront area, one respondent in Phoenix reported:

We don't talk about what's over there. It's just very desolate and ugly and they put all the heavy industry over there [...] there's a lot of public land there and there's not much that you would use for recreation whereas this could be a huge beautiful park or something (PHX-10).

Another respondent in New York called attention to a general management hurdle experienced throughout the city.

one of the travesties that comes along with [New York City's complex infrastructure] is that there's so much underground, including complete voids that we can't plant trees in the ground. So, what I really wanna see would be like a development [...] [of a] trees in containers program [...] (NYC-6).

This respondent was not alone in yearning for more forward thinking in urban forest decision making. Many respondents reported frustrations related to larger trends in urban planning, pointing out areas where design oversight has contributed to barren landscapes.

trees weren't even a part of the landscape design. [...] You can see trees in private property but nothing on these huge, especially next to these arterials where people have to walk to get to the things they need, there's just nothing. It's all concrete, all man made (PHX-10).

[...] back in these older neighborhoods, they have these really awesome 16-foot planting strips on these wide boulevards, but since it's such an older neighborhood and lower income, a lot of them are just collecting weeds, and I wish the city would come through and actually utilize these broad boulevards [...] (PHX-6).

Contributing nuance to this narrative, an additional Phoenix respondent expressed concern about particular planning 
practices that prioritize short-term investment in the urban forest to the detriment of the future landscape.

it's tending toward the movement of what I call disposable landscape, and that's where Phoenix has really gone in the last 20 years. Well, we'll plant it and it will grow, and in 10 years, we'll remove it all and we'll put in new landscape (PHX-11).

\section{Degradation}

Signs of degradation were cited as rationale for thirteen respondents when selecting least-preferred urban forest areas. A common indicator of degradation was a lack of vegetationfor some, a dearth of well-managed greenery indicated neglect and desolation.

the area around Luke Air Force Base is... Seems like a desolate wasteland. They have restrictions on what can be used from a plant type in a lot of those areas [...] it feels really dead (PHX-9).

When speaking with other respondents, however, urban spaces that lacked vegetation were associated with tangible impacts such as intense heat, lack of amenities for pedestrians, and high density of invasive species.

it was just so barren. When I try to walk, there's nowhere to walk to lunch, there weren't a lot of places. And it's hot and there's not a lot of trees [...] And you're on the most highest pedestrian [area] [...] (PHX-1).

Those kinds of invasive landscapes, or like vine lands that we still have in some of our woodlands, although we're getting better at that. That kind of thing depresses me, just 'cause I feel like we could do a better job managing that (NYC-3).

For one urban forester in Phoenix, his least preferred urban forest was not victim to any of these previous woes, but rather the presence of vandalism.

I didn't like maintaining it because the high vandalism rate in the park. And I planted, on purpose, very thorny trees in that park, because I was tired of them breaking all the limbs off of my trees (PHX-5).

The legacy of industrial activity was another common thread among respondents expressing their lack of preference for urban forest areas.

They're industrial corridors. They have very little vegetation. They were just planted at a time where, just because there's adjacent industrial development, even though there might be residences a half mile away, would just neglect the streetscape [...] (PHX-9).

In this excerpt, our respondent associates the presence of industry with neglect of the urban forest on the part of the municipality. Exploring this trend from another angle, a separate respondent expressed their lack of preference for parks installed near industrial areas.
I have this aversion to industrial parks [...] You see the plumes of smoke from tire recycling. It's just ugly, it's just awful (PHX-8).

Offering an interesting addition to this narrative, a New York urban forester highlighted the potential for urban forests to be overshadowed by environmental injustices.

I really don't like these areas, because they're less the forest than more just areas of what I think are just extreme environmental injustice (NYC-6).

This respondent was not alone in interpreting their observations of degraded urban forest areas as indicative of larger patterns of inequity and injustice. Another urban forester in New York expressed despair for a locally beloved park that was not receiving the financial support necessary for its upkeep.

it's in a very poor neighborhood [...] and it could be gorgeous but it is just run down and filled with litter and the people in the neighborhood really love it but they just don't have the time or the money to keep up with it and it's not gonna' have the kind of advocacy and fundraising around Central Park (NYC-1).

\section{DISCUSSION}

Urban forest preferences are a central aspect of how users experience the urban forest and a key ingredient in the movement toward contextually relevant and equitable urban forest governance (Rishbeth, 2001, 2004). Although various studies have investigated urban forest preferences among the general public (Fraser and Kenney, 2000; Tyrväinen et al., 2007; Peckham et al., 2013), we are not aware of other studies that have investigated urban forest practitioner preferences. This study examines the urban forest preferences of urban foresters and allied green practitioners in two U.S. cities, New York and Phoenix. Drawing on semi-structured interviews with 22 participants, we present initial findings on urban forest practitioner preference. We do not claim to represent the totality of practitioner urban forest preferences, but rather offer an exploratory analysis in the hope that it will suggest highlight potential trends in practitioner preferences, provide the grounding for future research in the field, and help illuminate the advantages of accounting for practitioner preference in urban forest governance. Urban foresters and related green practitioners possess important expertise and are key stakeholders in urban forest governance. It is essential to understand practitioner preferences to advance governance strategies that balance the professional knowledge of practitioners with the needs and desires of the public, and encourage an attention to equity in urban forest governance.

Outside of the findings we report, our study also illuminates the advantages that qualitative methods can offer urban forest preference research and contributes novel interpretive frames for future work. We drew on a suite of qualitative methods that encouraged engagement with the nuance of respondent perspectives and investigated the experiences that led to the formation and justification of preference. Throughout our 
interview process, we invited respondents to both express their preferences for urban forest attributes and to contextualize those preferences in terms of their local urban forest. In doing so, we went beyond acquiring a sense for the broad trends in our data and were able to appreciate and learn from the unique perspectives shared by each respondent. Attending to respondent narrative is essential, especially when considering a topic as bound to experience as the expression of preference (Kaplan, 1982). During analysis, our practice of thematic classification helped us to remain close to respondent answers and limited researcher influence on the definition of preference themes.

\section{Contextualizing the Expression of Urban Forest Practitioner Preference}

To contextualize the expression of preference among urban forest professionals, we place our key findings in conversation with existing urban forest preference scholarship. This literature exists within a broad array of disciplines and employs a wide range of methods. While certain examples of relevant scholarship have an explicit focus on preference (Schroeder, 1990; Koo et al., 2013; Arnberger and Eder, 2015; Ode Sang et al., 2016; Smiley et al., 2016), others frame their inquiry in terms of urban forest values (Jim and Chen, 2006; Peckham et al., 2013; Ordóñez and Duinker, 2014; Sinclair et al., 2014). Only select literature applies a qualitative methodology (Peckham et al., 2013; Ordóñez and Duinker, 2014; Sinclair et al., 2014; Smiley et al., 2016) and methods of analysis and research contexts vary. Interestingly, previous preference research conducted with the general public rarely pays explicit attention to attributes which relate to lack of preference. Many studies hint at attributes that may lead to a lack of preference (Peckham et al., 2013; Ordóñez and Duinker, 2014; Sinclair et al., 2014; Smiley et al., 2016); however, these findings are based on inference from respondent discussion of preferences rather than comprehensive inquiry exploring lack of preference.

Although some consideration for administration appears in the greater urban forest preference literature, residents across a multitude of studies tend not to express strong connections between accessibility and management, and their preference for urban forests (Koo et al., 2013; Sinclair et al., 2014). Accessibility is an especially rare determinant of preference among urban forest users. Only one study-focusing on the perspectives and experiences of historically marginalized residents-treats the subject in-depth, but even then, finds that concerns for access are eclipsed by a desire for increased park infrastructure and amenities (Smiley et al., 2016). Management appears as a point of preference more often, but, again is tied to questions of urban forest amenities, and similar to our findings, is influenced by local context (Jim and Chen, 2006; Koo et al., 2013; Sinclair et al., 2014; Arnberger and Eder, 2015; Smiley et al., 2016). These findings illuminate a clear divergence in the expression of preference among our respondents and those of earlier studies exploring user preferences. Whereas our respondents regularly connected their preference to administrative elements of the urban forest-most often in terms of accessibility and management-previous studies exploring preferences of the general public rarely noted such concerns. Although this finding may appear as common sense, it demonstrates an important relationship between urban forest practitioners' expertise and their experience of the urban forest. Our respondents generally approach their determination of preference from a systems-level perspective, considering elements of green spaces that transcend their personal experiences and integrating professional knowledge into their judgements. This finding, beyond illuminating a unique lens through which urban forest practitioners view the urban forest, reinforces the contention that the preferences of urban forest practitioners, while not of greater importance than those of the general public, offer unique insights of which the general public may not be aware or account for in their own determination of preference.

Myriad studies have found that naturalness is a common element of preference among respondents, and there is consistency across studies in how respondents and researchers characterized this often intangible element of the urban forest (Schroeder, 1990; Ode et al., 2009; Peckham et al., 2013; Ordóñez and Duinker, 2014; Sinclair et al., 2014; Ode Sang et al., 2016). In terms of physical attributes connected to naturalness, respondents in previous studies cite an abundance of diverse vegetation and large trees (Ordóñez and Duinker, 2014; Sinclair et al., 2014; Ode Sang et al., 2016) as well as related factors that contributed to a forest aesthetic (Schroeder, 1990; Peckham et al., 2013). Most often, however, studies have reported that preference for naturalness among urban forest users emanates from a sense of connection to nature (Peckham et al., 2013; Ordóñez and Duinker, 2014; Sinclair et al., 2014). These findings reveal a significant point of overlap between the expression of preference among our respondents and other urban forest users. Similar to the findings of earlier urban forest preference studies, when expressing elements of preference that were based in feeling and experience-such as perception of naturalness-our respondents tended to report anecdotes as opposed to observations. An interesting point of divergence, however, emerged in the frequency with which our respondents associated naturalness characteristics with elements of socioeconomic status. On multiple occasions, mature tree canopy was mentioned in tandem with the size of homes adjacent to the urban forest or, in Phoenix, the presence of irrigation systems. Our respondents, beyond their personal preference for urban forests boasting a mature tree canopy and abundant vegetation, showed clear recognition of the social conditions that enabled those amenities. Recognition of such associations have not been reported within previous urban forest user preference studies, suggesting a link between the expertise of our respondents and an increased knowledge of or attentiveness to the sociospatial factors that relate to preference. This finding illuminates the influence of expertise on expression of preference among urban forest practitioners: our respondents showed an increased tendency to think holistically about the urban forest and how it relates to and serves the surrounding community. Moreover, respondents revealed a capacity both to think reflexively about the inequitable distribution of those urban forest elements they find most preferable and to integrate considerations for equity when forming and justifying their urban forest preferences.

Recreational amenities are a common determinant of preference in studies surveying general urban forest users (Jim and Chen, 2006; Koo et al., 2013; Sinclair et al., 2014; Arnberger and Eder, 2015; Japelj et al., 2016). That said, there is little 
consistency in what defines recreation or recreational spacewhile some researchers discuss outstanding trees and forest openings (Japelj et al., 2016) others cite calls for increases in trails and other points of interaction with the urban forest (Sinclair et al., 2014). No matter the context, however, urban forest users across contexts express a desire for a range of recreational land uses (Jim and Chen, 2006; Koo et al., 2013; Sinclair et al., 2014; Arnberger and Eder, 2015; Japelj et al., 2016). This trend aligns with our own finding that spatial diversity was favored among urban forest professionals because of the variety of experiences and modes of engagement it offered users. Our respondents considered spatial diversity as a measure of an urban forest's capacity to meet resident needs, just as previous studies have suggested that the general public appreciates spatially diverse urban forests for the range of uses they support. Although there are significant parallels in how the presence of recreational amenities related to urban forest preference among our respondents and the general public, our findings suggest that practitioners think about spatial diversity in terms of benefits offered to the general public as opposed to themselves. In other words, they do not reflect on the potential for personal recreation, but the capacity of the urban forest to provide recreational opportunities to other users. Again, this highlights a systems-level perspective rooted in respondents' tendencies to think beyond personal experience and consider the urban forest as a whole landscape.

Social benefits provided by the urban forest were common determinants of preference both among our respondents and within the urban forest preference literature generally (Peckham et al., 2013; Ordóñez and Duinker, 2014; Sinclair et al., 2014; Smiley et al., 2016). Although previous research classifies social impacts of the urban forest in a variety of ways, a few common themes emerged between our results and those of previous preference studies-namely, that preferred urban forests offered a sense of escape and a place for various forms of community engagement and recreation across socio-economic status (Peckham et al., 2013; Ordóñez and Duinker, 2014; Sinclair et al., 2014; Smiley et al., 2016). Many respondents, both in our own research and in previous preference studies, praised the capacity of urban forests to offer a sense of escape to users. This feeling was elicited by a variety of physical attributes such as dense vegetation and non-urban terrain (e.g., gravel paths or trails)-these qualities were thought to give the impression of distance from the urban world (Sinclair et al., 2014). Along with the creation of spaces that felt outside the city, respondents preferred urban forests that cultivated a unique sense of place and community (Peckham et al., 2013; Sinclair et al., 2014). The striking similarities we found between previous urban forest preference research and our own suggests that, when considering preference along the axis of social benefit, our respondents were less likely to justify their preference in terms of the systems-level thinking we had found previously, but rather offered reflections on their personal lived experiences within urban forest spaces. This departure from a systems perspective suggests that our respondents were more likely to process the sense of place and community provided by urban forests as an individualistic phenomenon. In other words, their experience of social benefits offered by the urban forest was viewed as unique to them, and thus expressed through anecdote and reflection.

\section{Implications of Findings on Urban Forest Governance and Governance Theory}

Our findings offer an initial indication that although there is no hard line separating the formation of urban forest preference among urban forest practitioners and the general public, urban forest practitioners draw on a variety of training and professional experiences to inform their urban forest perceptions. Whereas previous research has found that preference is typically expressed in terms of personal lived experience (Peckham et al., 2013; Sinclair et al., 2014), our respondents showed a tendency to bring a systems or landscape-level approach to their perceptions of and preferences for urban forest spaces. This understanding of urban forest practitioner preference begins to explain our respondents' focus on administrative and management issues and the important role of socioeconomic context in their expressions of preference. In addition, it makes sense of points of contrast between our findings and those of previous studies exploring preferences for urban forests among the general public. In illuminating these fundamental differences in the development and expression of preference, we are not implying that practitioner preference is more valuable when determining urban forest governance strategies. Rather, we mean to highlight the ways in which this knowledge pool complements the recorded preferences of the general public. Understanding these areas of divergence between urban forest professionals' and the public's preferences offers a pathway toward more fruitful discussions of equitable urban forest governance. Urban foresters and allied green practitioners need to offer their urban forest expertise and systems-level thinking to urban forest governance while ensuring that their preferences, and the dominant institutional greening discourses in their municipalities, do not obscure the diversity of urban forest preferences held by the general public. An understanding of the patterns of influence guiding the formation of preference among urban forest practitioners is a first step toward this goal.

Our findings highlight the utility of a mosaic approach to urban forest governance. Mosaic governance is a contextsensitive style of governance that supports the inclusion of diverse preferences across an urban forest landscape, combining the important systems-level perspectives and preferences of urban forest practitioners with the context-rich preferences of local communities (Buijs et al., 2016; Gulsrud et al., 2018). It allows for and facilitates a mosaic of diverse governance arrangements and management approaches within the urban landscape that reflects the needs and preferences of local urban forest users. It does not strive for a "one size fits all" approach to urban forestry but allows for urban forest practitioner preferences and expertise to inform urban forest planning and management, while remaining close to and supporting local preferences. This approach operationalizes the concept of balancing individual and collective rights articulated by theories of green equity (Heynen, 2003; Swyngedouw and Heynen, 2003), and may facilitate recognitional equity in urban forest 
governance (Young, 1990). It allows for the important role that municipal and regional governments, and urban forest practitioners, play in urban greening while supporting placebased governance that balances urban forester preferences with those of the local public (Gulsrud et al., 2018). Our results highlight the need for such place-based governance approaches that ensure local urban forest preferences are integrated with those of urban forest professionals, facilitating local urban forests that reflect the preferences of local communities while benefiting from the expertise of urban foresters.

\section{Limitations of Research and Opportunities for Future Inquiry}

Throughout our study, we strove to maintain awareness of the limitations of our research methods and data. A clear strength of our approach was our capacity to attend to the nuance in how respondents expressed and justified their urban forest preferences. Such in-depth engagement with respondents, however, placed limitations on both our sample size and the range of urban contexts within which we could conduct our research. What's more, in framing our interview questions, we made an intentional decision to focus on urban forest preferences. Although this may not seem like a limiting choice, within the greater realm of urban forest preference research, there is little consistency in how scholars define or investigate preference. Going forward, it is essential that researchers begin to formalize a framework for investigating and characterizing preference so as to increase the possibility for knowledge sharing across contexts.

Our study illuminates a novel path for future urban forest preference inquiry. Preferences are but one aspect of the knowledge cultures, management styles, discourses, and identities that shape urban forest governance processes (Jönsson and Gustavsson, 2002; Blicharska and Van Herzele, 2015). Thus, future research on the role of urban forest preferences in urban forest governance should account for these additional influences on urban forest governance, and analyze the ways in which preference interacts with other aspects of collective decision making. In addition, explicit analyses of the links between preferences and policy outcomes would provide helpful insights into governance processes and approaches to achieving recognitional equity in practice.

\section{Conclusion}

Urban forest preferences, and their inclusion in decision making, are central to the advancement of urban green equity and just urban forest governance. Preferences reflect the experiences, needs, and values of urban forest stakeholders and must be understood so that they can drive successful urban forest management. Our findings offer a preliminary glimpse into the formation, justification, and expression of urban forest

\section{REFERENCES}

Alvarez, S., Soto, J., Escobedo, F., Lai, J., and Adams, D. (2018). "Heterogeneous preferences for urban forest attributes: a latent class approach," in 2018 practitioner preference and reveal an important systemslevel perspective rooted in practitioner expertise. While the recorded perspectives illuminate the importance of urban forest practitioner preference as a guide for urban forest management and decision making, it is essential that these preferences do not eclipse those of other urban forest stakeholders, such as local residents. Urban forest governance systems that facilitate recognitional equity, such as mosaic governance systems, offer a pathway toward balancing and bringing together the systems-level perspectives of urban forest professionals with the heterogeneous place-based preferences of other urban forest stakeholders. By facilitating place-based governance and bringing diverse voices and preferences into urban forest decision processes from the outset, such approaches can help create urban forests that work for everyone, meeting the collective and individual needs of urban societies. It is our hope that this research will stimulate further inquiry on the role of urban forest preferences in equitable governance and a more reflexive practice of urban forestry.

\section{DATA AVAILABILITY STATEMENT}

The raw data supporting the conclusions of this article will be made available by the authors, without undue reservation.

\section{ETHICS STATEMENT}

The studies involving human participants were reviewed and approved by the University of British Columbia-Behavioral Research Ethics Board (BREB) Approval Certificate Number H16-02583-A002. The patients/participants provided their written informed consent to participate in this study.

\section{AUTHOR CONTRIBUTIONS}

CM performed data analysis and wrote the introduction and methods. DS interpreted findings through governance lens and adapted the introduction and methods to fit this lens. DS wrote the results and much of the discussion section. LN conducted data collection and supervised data analysis and paper composition. LN wrote significant portions of the discussion section, the conclusion, and the abstract. All authors contributed to the article and approved the submitted version.

\section{SUPPLEMENTARY MATERIAL}

The Supplementary Material for this article can be found online at: https://www.frontiersin.org/articles/10.3389/frsc.2020. 572572/full\#supplementary-material
Southern Agricultural Economics Association Annual Meeting Session 13: Economics of Forest Systems, eds M. Reed, and S. Saghaian (Jacksonville, FL). Arnberger, A., Allex, B., Eder, R., Ebenberger, M., Wanka, A., Kolland, F., et al. (2017). Elderly resident's uses of and preferences for urban 
green spaces during heat periods. Urban For. Urban Green 21, 102-115. doi: 10.1016/j.ufug.2016.11.012

Arnberger, A., and Eder, R. (2012). The influence of green space on community attachment of urban and suburban residents. Urban For. Urban Green 11, 41-49. doi: 10.1016/j.ufug.2011.11.003

Arnberger, A., and Eder, R. (2015). Are urban visitors' general preferences for green-spaces similar to their preferences when seeking stress relief? Urban For. Urban Green 14, 872-882. doi: 10.1016/j.ufug.2015.07.005

Asah, S. T., and Blahna, D. J. (2020). Involving stakeholders' knowledge in codesigning social valuations of biodiversity and ecosystem services: implications for decision-making. Ecosystems 23, 324-337. doi: 10.1007/s10021-019-00405-6

Blicharska, M., and Van Herzele, A. (2015). What a forest? Whose forest? Struggles over concepts and meanings in the debate about the conservation of the Białowieza Forest in Poland. For. Policy Econ. 57, 22-30. doi: 10.1016/j.forpol.2015.04.003

Braun, V., and Clarke, V. (2006). Using thematic analysis in psychology. Qual. Res. Psychol. 3, 77-101. doi: 10.1191/1478088706qp063oa

Brenner, N., and Schmid, C. (2017). "Planetary urbanization," in The Globalizing Cities Reader, eds X. Ren and R. Keil (London: Routledge), 449-452.

Brown, B., Perkins, D. D., and Brown, G. (2003). Place attachment in a revitalizing neighborhood: individual and block levels of analysis. J. Environ. Psychol. 23, 259-271. doi: 10.1016/S0272-4944(02)00117-2

Buijs, A. E., Mattijssen, T. J. M., Van der Jagt, A. P. N., Ambrose-oji, B., Andersson, E., Elands, B. H. M., et al. (2016). Active citizenship for urban green infrastructure: fostering the diversity and dynamics of citizen contributions through mosaic governance. Curr. Opin. Environ. Sustain. 22, 1-6. doi: 10.1016/j.cosust.2017.01.002

City of Phoenix (2010). Tree and Shade Master Plan. Phoenix, AZ.

City of Phoenix (2020). Learn About Phoenix's Urban Forest. Park. Recreat. Phoenix, AZ.

Conway, T. M., and Vander Vecht, J. (2015). Growing a diverse urban forest: Species selection decisions by practitioners planting and supplying trees. Landsc. Urban Plan. 138, 1-10. doi: 10.1016/j.landurbplan.2015.01.007

Creswell, J. W. (2018). Qualitative Inquiry \& Research Design : Choosing Among Five Approaches, 4th Edn. Los Angeles, CA: SAGE Publications.

Dodman, D. (2017). "Environment and urbanization," in International Encyclopedia of Geography: People, the Earth, Environment and Technology, eds D. Richardson, N. Castree, M. F. Goodchild, A. Kobayashi, W. Liu, and R. A. Marston (SAGE Publications Ltd). doi: 10.1002/9781118786352.wbieg0623

Du Bois, J. W., Schuetze-Coburn, S., Cumming, S., and Paolino, D. (1993). Outline of discourse transcription. Talk. Data Transcr. Coding Discourse Res (Hillsdale, NJ: Lawrence Ebrium), 45-89.

Elmqvist, T., Setälä, H., Handel, S. N., van der Ploeg, S., Aronson, J., Blignaut, J. N., et al. (2015). Benefits of restoring ecosystem services in urban areas. Curr. Opin. Environ. Sustain. 14, 101-108. doi: 10.1016/j.cosust.2015.05.001

Escobedo, F. J., and Nowak, D. J. (2009). Spatial heterogeneity and air pollution removal by an urban forest. Landsc. Urban Plan 90, 102-110. doi: 10.1016/j.landurbplan.2008.10.021

Fontaine, L. C., and Larson, B. M. H. (2016). The right tree at the right place? Exploring urban foresters' perceptions of assisted migration. Urban For. Urban Green. 18, 221-227. doi: 10.1016/j.ufug.2016.06.010

Fontana, A., and Frey, J. H. (2005). "Interview from neutral science to political involvment," in The Sage Handbook of Qualitative Research, eds N. K. Denzin and Y. S. Lincoln (SAGE Publications Ltd), 695-727.

Fraser, E. D. G., and Kenney, W. A. (2000). Cultural background and landscape history as factors affecting perceptions of the urban forest. J. Arboric. 26, 106-113.

Greenspan, H., and Bolkosky, S. (2006). When is an interview an interview? Notes from listening to holocaust survivors. Poet. Today 27, 431-449. doi: 10.1215/03335372-2005-012

Gulsrud, N. M., Hertzog, K., and Shears, I. (2018). Innovative urban forestry governance in Melbourne?: Investigating "green placemaking" as a naturebased solution. Environ. Res. 161, 158-167. doi: 10.1016/j.envres.2017.11.005

Heynen, N., Perkins, H. A., and Roy, P. (2006). The political ecology of uneven urban green space: the impact of political economy on race and ethnicity in producing environmental inequality in milwaukee. Urban Aff. Rev. 42, 3-25. doi: $10.1177 / 1078087406290729$
Heynen, N. C. (2003). The scalar production of injustice within the urban forest. Antipode 35, 980-998. doi: 10.1111/j.1467-8330.2003.00367.x

Japelj, A., Mavsar, R., Hodges, D., Kovač, M., and Juvančič, L. (2016). Latent preferences of residents regarding an urban forest recreation setting in Ljubljana, Slovenia. For. Policy Econ. 71, 71-79. doi: 10.1016/j.forpol.2015.10.003

Jim, C. Y., and Chen, W. Y. (2006). Recreation-amenity use and contingent valuation of urban greenspaces in Guangzhou, China. Landsc. Urban Plan. 75, 81-96. doi: 10.1016/j.landurbplan.2004.08.008

Jönsson, A., and Gustavsson, R. (2002). Management styles and knowledge cultures, past, present and future, related to multiple-use and urban woodlands. Urban For. Urban Green. 1, 39-47. doi: 10.1078/1618-8667-00005

Kaplan, S. (1982). Where cognition and affect meet: a theoretical analysis of preference. EDRA Environ. Des. Res. Assoc. 13, 183-188.

Konijnendijk, C. C., Ricard, R. M., Kenney, A., and Randrup, T. B. (2006). Defining urban forestry-a comparative perspective of North America and Europe. Urban For. Urban Green 4, 93-103. doi: 10.1016/j.ufug.2005.11.003

Koo, J.-C. C., Park, M. S., and Youn, Y.-C. C. (2013). Preferences of urban dwellers on urban forest recreational services in South Korea. Urban For. Urban Green 12, 200-210. doi: 10.1016/j.ufug.2013.02.005

Landry, S. M., and Chakraborty, J. (2009). Street trees and equity: evaluating the spatial distribution of an urban amenity. Environ. Plan. A 41, 2651-2670. doi: $10.1068 / \mathrm{a} 41236$

Lindemann, J. (2019). Gardens and green spaces: placemaking and black entrepreneurialism in Cleveland, Ohio. Agric. Human Values 36, 867-878. doi: 10.1007/s10460-019-09947-w

Maxwell, J. A. (2013). Qualitative Research Design: An Interactive Approach, 3rd Edn. Thousand Oaks, CA: SAGE Publications.

McPhearson, P. T., Feller, M., Felson, A., Karty, R., Lu, J. W. T., Palmer, M. I., et al. (2016). "Assessing the effects of the urban forest restoration effort of MillionTreesNYC on the structure and functioning of New York City ecosystems," in Urban Forests: Ecosystem Services and Management, ed. J. Blum (New York, NY: Apple Academic Press), 265-286.

National Oceanic and Atmospheric Administration (2019a). NOWData. New York, NY: National Oceanic and Atmospheric Administration.

National Oceanic and Atmospheric Administration (2019b). NOWData. Phoenix, $A Z$ : National Oceanic and Atmospheric Administration

Nesbitt, L., Hotte, N., Barron, S., Cowan, J., and Sheppard, S. R. J. (2017). The social and economic value of cultural ecosystem services provided by urban forests in North America: a review and suggestions for future research. Urban For. Urban Green 25, 103-111. doi: 10.1016/j.ufug.2017.05.005

Nesbitt, L., Meitner, M. J., Girling, C., Sheppard, S. R. J., and Lu, Y. (2019). Who has access to urban vegetation? A spatial analysis of distributional green equity in 10 US cities. Landsc. Urban Plan. 181, 51-79. doi: 10.1016/j.landurbplan.2018.08.007

Nesbitt, L., Meitner, M. J., Sheppard, S. R. J., and Girling, C. (2018). The dimensions of urban green equity: a framework for analysis. Urban For. Urban Green 34, 240-248. doi: 10.1016/j.ufug.2018.07.009

New York City Parks and Recreation (2019a). About Parks: NYC Parks. New York City Parks and Recreation.

New York City Parks and Recreation (2019b). Partners: NYC Parks. New York City Parks and Recreation

New York City Parks and Recreation. (2014). NYC Parks: Framework for an Equitable Future. New York, NY: New York City Parks and Recreation.

Nowak, D. J., Bodine, A. R., Hoehn, Robert E., I., Ellis, A., Hirabayashi, S., et al. (2018). The Urban Forest of New York City. US Forest Service Northern Research Center. doi: 10.2737/NRS-RB-117

Nowak, D. J., and Crane, D. E. (2002). Carbon storage and sequestration by urban trees in the USA. Environ. Pollut. 116, 381-389. doi: 10.1016/S0269-7491(01)00214-7

Ode Sang, Å., Knez, I., Gunnarsson, B., and Hedblom, M. (2016). The effects of naturalness, gender, and age on how urban green space is perceived and used. Urban For. Urban Green 18, 268-276. doi: 10.1016/j.ufug.2016. 06.008

Ode, Å., Fry, G., Tveit, M. S., Messager, P., and Miller, D. (2009). Indicators of perceived naturalness as drivers of landscape preference. J. Environ. Manage. 90, 375-383. doi: 10.1016/j.jenvman.2007.10.013 
Ordóñez, C., and Duinker, P. N. (2014). Urban forest values of the citizenry in three colombian cities. Soc. Nat. Resour. 27, 834-849. doi: 10.1080/08941920.2014.905891

Palinkas, L. A., Horwitz, S. M., Green, C. A., Wisdom, J. P., Duan, N., and Hoadwood, K. (2015). Purposeful sampling for qualitative data collection and analysis in mixed method implementation research. Adm. Policy Ment. Heal. Ment. Heal. Serv. Res. 42, 533-544. doi: 10.1007/s10488-013-0528-y

Peckham, S. C., Duinker, P. N., and Ordóñez, C. (2013). Urban forest values in Canada: views of citizens in Calgary and Halifax. Urban For. Urban Green 12, 154-162. doi: 10.1016/j.ufug.2013.01.001

Riechers, M., Barkmann, J., and Tscharntke, T. (2016). Perceptions of cultural ecosystem services from urban green. Ecosyst. Serv. 17, 33-39. doi: 10.1016/j.ecoser.2015.11.007

Rishbeth, C. (2001). Ethnic minority groups and the design of public open space: an inclusive landscape? Landsc. Res. 26, 351-366. doi: 10.1080/01426390120090148

Rishbeth, C. (2004). Ethno-cultural representation in the urban landscape. J. Urban Des. 9, 311-333. doi: 10.1080/1357480042000283878

Schensul, S., Schensul, J. J., and LeCompte, M. D. (1999). In-depth, openended interviewing; semistructured interviewing. Essent. Ethnogr. Methods Obs. Interviews Quest (Altamira Press), 121-164.

Schroeder, H. W. (1990). Perceptions and preferences of urban forest users. J. Arboric. 16, 58-61.

Schwarz, K., Fragkias, M., Boone, C. G., Zhou, W., McHale, M., Grove, J. M., et al. (2015). Trees grow on money: urban tree canopy cover and environmental justice. PLoS ONE 10:e0122051. doi: 10.1371/journal.pone.0122051

Shanahan, D. F., Lin, B. B., Bush, R., Gaston, K. J., Dean, J. H., Barber, E., et al. (2015). Toward improved public health outcomes from urban nature. Am. J. Public Health 105, 470-477. doi: 10.2105/AJPH.2014. 302324

Sinclair, A. J., Diduck, J., and Duinker, P. N. (2014). Elicitation of urban forest values from residents of Winnipeg, Canada. Can. J. For. Res. 44, 922-930. doi: 10.1139/cjfr-2014-0016

Smiley, K. T., Sharma, T., Steinberg, A., Hodges-Copple, S., Jacobson, E., and Matveeva, L. (2016). More inclusive parks planning: park quality and preferences for park access and amenities. Environ. Justice 9, 1-7. doi: 10.1089/env.2015.0030

Sultana, F. (2007). Participatory ethics: negotiating fieldwork dilemmas in international research. ACME Editor. Collect. 6, 374-385.
Swyngedouw, E., and Heynen, N. C. (2003). Urban political ecology, justice and the politics of scale. Antipode 35, 898-918. doi: 10.1111/j.1467-8330.2003.00364.x

Tyrväinen, L., Mäkinen, K., and Schipperijn, J. (2007). Tools for mapping social values of urban woodlands and other green areas. Landsc. Urban Plan. 79, 5-19. doi: 10.1016/j.landurbplan.2006.03.003

United Nations (2018). World Urbanization Prospects: The 2018 Revision. United Nations.

United States Census Bureau (2017). QuickFacts. United States Census Bureau

Vaivio, J. (2012). "Interviews-learning the craft of qualitative research interviewing," in European Accounting Review, eds S. Brinkmann and S. Kvale (Thousand Oaks, CA: SAGE Publications), 186-189.

Voskamp, I. M., and van de Ven, F. H. M. (2015). Planning support system for climate adaptation: composing effective sets of blue-green measures to reduce urban vulnerability to extreme weather events. Build. Environ. 83, 159-167. doi: 10.1016/j.buildenv.2014.07.018

Weiss, C. C., Purciel, M., Bader, M., Quinn, J. W., Lovasi, G., Neckerman, K. M., et al. (2011). Reconsidering access: Park facilities and neighborhood disamenities in New York City. J. Urban Heal. 88, 297-310. doi: 10.1007/s11524-011-9551-z

Wolf, D. (1996). "Situating feminist dilemmas in fieldwork," in Feminist Dilemmas in Fieldwork, ed. D. Wolf (New York, NY: Routledge), 1-55.

Wolf, K. L., Measells, M. K., Grado, S. C., and Robbins, A. S. T. (2015). Economic values of metro nature health benefits: a life course approach. Urban For. Urban Green 14, 694-701. doi: 10.1016/j.ufug.2015.06.009

Young, I. M. (1990). Justice and the Politics of Difference. Princeton, NY: Princeton University Press.

Young, R. F. (2010). Managing municipal green space for ecosystem services. Urban For. Urban Green. 9, 313-321. doi: 10.1016/j.ufug.2010.06.007

Conflict of Interest: The authors declare that the research was conducted in the absence of any commercial or financial relationships that could be construed as a potential conflict of interest.

Copyright (C) 2020 Sax, Manson and Nesbitt. This is an open-access article distributed under the terms of the Creative Commons Attribution License (CC BY). The use, distribution or reproduction in other forums is permitted, provided the original author(s) and the copyright owner(s) are credited and that the original publication in this journal is cited, in accordance with accepted academic practice. No use, distribution or reproduction is permitted which does not comply with these terms. 